\title{
Comparative study of intrathecal bupivacaine $0.5 \%$ with bupivacaine $0.5 \%$ and buprenorphine low dose for postoperative analgesia in lower abdominal surgeries
}

\author{
B. Dinakar Rao*, K. Chandra Prakash
}

Department of Anesthesia, Mallareddy institute of medical sciences, Hyderabad, India

Received: 20 November 2015

Accepted: 16 December 2015

*Correspondence:

Dr. B. Dinakar Rao,

E-mail dboothpur@icloud.com

Copyright: (C) the author(s), publisher and licensee Medip Academy. This is an open-access article distributed under the terms of the Creative Commons Attribution Non-Commercial License, which permits unrestricted non-commercial use, distribution, and reproduction in any medium, provided the original work is properly cited.

\begin{abstract}
Background: Opiods, like buprenorphine, have been widely used for providing pain relief postoperatively and their advantages of neuraxial narcotics over systemic narcotics are well established. When compared to local anaesthetics, they offer good analgesia while allowing early ambulation of the patient by sparing sympathetic and motor nerves. This study was conducted to compare the efficacy of bupivacaine alone and in combination with low dosage of buprenorphine.

Methods: 80 patients between the ages 20-60 undergoing lower abdominal surgeries were divided into 2 groups of 40 each after taking detailed history and undergoing the necessary preliminary tests. Patients in the Group I was given $17.5 \mathrm{mg}$ of $0.5 \%$ Hyperbaric Bupivacaine along with 60ug of Buprenorphine. The patients in Group II received $17.5 \mathrm{mg}$ of $0.5 \%$ Hyperbaric Bupivacaine. Onset and duration of analgesia were recorded. The efficacy of analgesia was recorded based on VAS score. Side effects, time of recovery also were noted.

Results: In this retrospective study we found that incidence of colorectal carcinoma is more between 40-60 years of age with male predominance; lymph node metastasis is more than metastasis in any other sites. CT scan can diagnose lymphatic metastasis and infiltration in surrounding tissue more accurately. Percentage of sphincter saving procedure was low in rectal malignancies in our study.

Conclusions: The onset of analgesia was within 5 minutes in $100 \%$ of the cases in Group I while in Group II it was upto 9 minutes. The mean of the duration of analgesia was $15 \mathrm{~h} 33 \mathrm{mins}$ and $3 \mathrm{~h} 18 \mathrm{mins}$ in Group I and II respectively. The pain scoring through VAS in the 2 groups showed that most of the patients in Group I had 0 to mild pain till about 12 hours while in Group II the analgesic effect was felt only till the first 2 hours. The supplementary analgesic was required on Group II within 4 hours post operatively while in Group I the requirement was only after 12 hours. The major side effect among the patients was vomiting and nausea in 12 patients in Group I followed by urinary retention in 6 patients. While in Group II only 6 patients had nausea and no other side effect. Pruritis was observed in 1 patient in Group I Respiratory distress, drowsiness, headache and backache was not observed in any of the cases.
\end{abstract}

Keywords: Bupivacaine, Buprenorphine, Post-operative analgesia, Lower abdominal surgeries, Comparison

\section{INTRODUCTION}

Pain is one of the most common and uncomfortable consequences of a surgery, feared by all. Effective and rapid relief from pain is always a challenge, but is necessary for alleviating nocioception - induced responses like endocrine metabolic responses to surgery, autonomic reflexes with adverse effects on organ function, reflexes leading to muscle spasm, and other undesirable results. ${ }^{1}$ 
Spinal block is the first choice of anaesthesia for lower abdominal surgeries, because of its rapid onset, superior blockade action, low risk of infection, less failure rates and cost effectiveness, though it does have drawbacks like shorter duration of block and lack of post-operative analgesia.

In the recent past, the use of intrathecal adjuvants have gained a lot of acclaim as they prolong the duration of block, there is a better success rate, better patient satisfaction and faster recovery as well as being cost effective. This enables the patients to return to their normal activity more quickly. ${ }^{2}$

Opiods have been widely used for providing pain relief postoperatively and their advantages of neuraxial narcotics over systemic narcotics are well established. ${ }^{3}$ When compared to local anaesthetics, they offer good analgesia while allowing early ambulation of the patient by sparing sympathetic and motor nerves ${ }^{4}$. Buprenorphine is a long acting, highly lipophilic opioid, which has proved to be a promising analgesic, by epidural and intrathecal route. ${ }^{5,6}$ It is found to be about 25 times more potent than morphine and has a low level of physical dependence. ${ }^{7}$

Lanz et al, in a study, demonstrate that buprenorphine, when administered intrathecally, produces no adverse reactions and is compatible with CSF.

The aim of this study was to compare the efficacy of intrathecal bupivacaine and low dose of buprenorphine with bupivacaine for post-operative analgesia.

\section{METHODS}

This study was performed in the Department of Anaesthesia at Mallareddy institute of medical sciences over a period of two years. 80 patients belonging to the American Society of Anaesthesiologists classification Grade I and II between the ages 20 - 60 years were included in the study. They were divided randomly into 2 groups of 40 each. Group I is given $0.5 \%$ hyperbaric bupivacaine plus buprenorphine and Group II received $0.5 \%$ hyperbaric bupivacaine intrathecally.

Detailed history and preoperative examinations were performed on all patients, including routine investigations like urine analysis, blood urea, blood sugar, bleeding time, clotting time, ECG and X-ray chest were performed for all the patients. Patients with systemic disorders, neurological disorders, metabolic disorders, bleeding diathesis and pregnant women were excluded from the study.

Prior to the scheduled operations, the nature of study was explained to the patients and the relatives in detail and an informed consent was taken from all the patients. They were fasted for a minimum of 6 hours before the surgery and were not premedicated with analgesics and sedatives.
Blood pressure, pulse rate and respiratory rate was recorded.

All patients were preloaded with $500 \mathrm{ml}$ of Ringer's Lactate. Under full aseptic conditions, a lumbar puncture was performed at the level of L3-L4 interspace using 23 gauze needle. Patients in the Group I was given $17.5 \mathrm{mg}$ of $0.5 \%$ Hyperbaric Bupivacaine along with 60ug of Buprenorphine.

The patients in Group II received $17.5 \mathrm{mg}$ of $0.5 \%$ Hyperbaric Bupivacaine.

Immediately after the administrations, the patient was placed in a horizontal position and onset of analgesia by loss of pain to pin prick and inability to raise the lower limb, degree and level of sensory blockade, degree of motor blockade, respiratory rate, duration and quality of post operational analgesia were recorded. Hemodynamic changes like pulse rate, blood pressure every 5 minutes interval for the first 30 minutes, there after every 15 minutes were recorded for the rest of the surgical procedure. Post operatively, they were recorded every 2 hours up to 12 hours and at 4 hourly intervals for 24 hours.

Side effects such as drowsiness, respiratory depression, itching, urinary retention, vomiting, headache and perspiration were also noted.

Duration of post-operative pain relief was assessed by noting the time of disappearance of pain after injection of drug to the time of reappearance of the pain. Efficacy was assessed by using a visual analogue scale at 4 hourly intervals for 24 hours. Score ' 0 ' represents no pain and score 10 represents the maximum permissible pain. With any score of more than 6 , the patients were administered supplementary analgesics and this was taken as the end point. Scores of 1,2,3 were considered as mild pain, 4,5,6 as moderate pain and 7,8,9, as severe pain. Side effects were noted and the results were analyzed.

\section{RESULTS}

Of the total 40 patients in Group I, 19 were males and 21 were females. In Group II, 18 were males and 22 were females (Figure1).

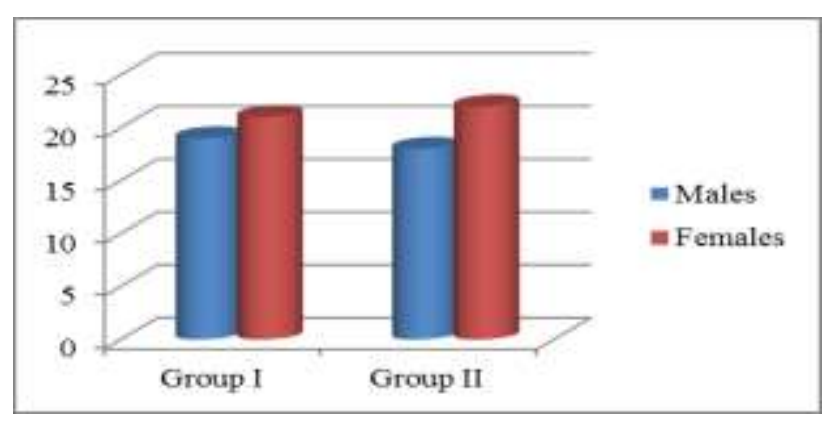

Figure 1: Sex wise distribution of patients. 
Most of the patients were of the age group $31-40$ years (Figure 2).

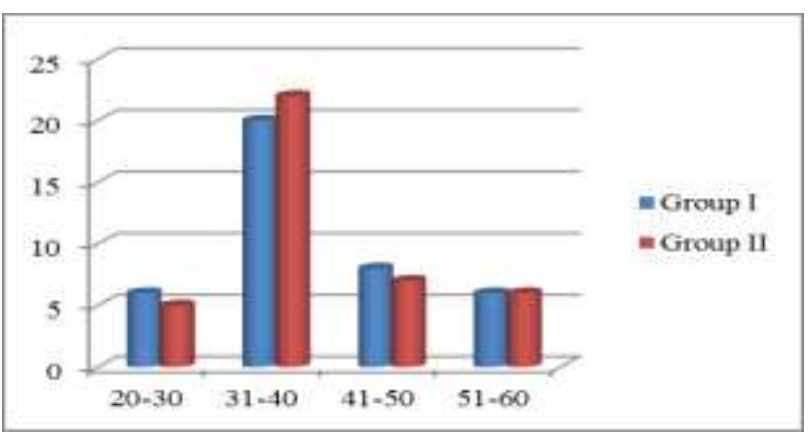

Figure 2: Age wise distribution of the patients.

The onset of analgesia was within 5 minutes (mean 2.86 min) in $100 \%$ of the cases in Group I while in Group II it was upto 9 minutes (Mean $5.8 \mathrm{~min}$ ) with $\mathrm{p}$ value $<0.001$ (Table 1).

Table 1: Onset of analgesia among patients.

\begin{tabular}{|lll|}
\hline Minutes & Group I & Group II \\
\hline $0-2$ & $16(40 \%)$ & 0 \\
\hline $3-5$ & $24(60 \%)$ & $20(50 \%)$ \\
\hline $6-8$ & 0 & $16(40 \%)$ \\
\hline $9-10$ & 0 & $4(10 \%)$ \\
\hline Total & 40 & 40 \\
\hline Mean & $2.86 \pm 0.92$ & $5.8 \pm 1.5$ \\
\hline
\end{tabular}

The duration of analgesia was also statistically significant. Group I showed a duration of above 7 hours of duration (mean $=15 \mathrm{~h} \mathrm{33mins)}$ while it was between 0-6 hours in Group II (mean $=3 \mathrm{~h} 18 \mathrm{~min}$ ) (Table 2).

Table 2: Duration of analgesia.

\begin{tabular}{|lll|}
\hline Hours & Group I & Group II \\
\hline $0-3$ & 0 & $17(42.5 \%)$ \\
\hline $4-6$ & 0 & $23(57.5 \%)$ \\
\hline $7-12$ & $14(35 \%)$ & 0 \\
\hline $13-18$ & $16(40 \%)$ & 0 \\
\hline $19-24$ & $8(20 \%)$ & 0 \\
\hline$>24$ & $2(5 \%)$ & 0 \\
\hline Total & 40 & 40 \\
\hline Mean & 15 h 33 mins & 3 h 18 mins \\
\hline
\end{tabular}

The pain scoring through VAS in the 2 groups showed that most of the patients in Group I had 0 to mild pain till about 12 hours while in Group II the analgesic effect was felt only till the first 2 hours. The supplementary analgesic was required on Group II within 4 hours post operatively while in Group I the requirement was only after 12 hours (Table 3). Pain at 10 VAS score was not seen in any of the cases.

The major side effect among the patients was vomiting and nausea in 12 patients in Group I followed by urinary retention in 6 patients. While in Group II only 6 patients had nausea and no other side effect. Pruritis was observed in 1 patient in Group I. (Figure 3) Respiratory distress, drowsiness, headache and backache was looked for but was observed in none of the patients in both the groups.

Table 3: Efficacy of analgesia.

\begin{tabular}{|c|c|c|c|c|c|c|c|c|}
\hline \multirow[t]{2}{*}{$\begin{array}{l}\text { Post } \\
\text { op- } \\
\text { period }\end{array}$} & \multicolumn{2}{|c|}{0} & \multicolumn{2}{|c|}{$\begin{array}{l}\text { Mild } \\
1,2,3\end{array}$} & \multicolumn{2}{|c|}{$\begin{array}{c}\text { Moderate } \\
4,5,6\end{array}$} & \multicolumn{2}{|c|}{$\begin{array}{l}\text { Severe } \\
\mathbf{7 , 8 , 9}\end{array}$} \\
\hline & Group I & Group II & Group I & Group II & Group I & Group II & Group I & Group II \\
\hline 0 & $\begin{array}{l}40 \\
(100 \%)\end{array}$ & $\begin{array}{l}40 \\
(100 \%)\end{array}$ & 0 & 0 & 0 & 0 & 0 & 0 \\
\hline 2 & $\begin{array}{l}40 \\
(100 \%)\end{array}$ & $\begin{array}{l}37 \\
(92.5 \%)\end{array}$ & 0 & $\begin{array}{l}3 \\
(7.5 \%)\end{array}$ & 0 & 0 & 0 & 0 \\
\hline 4 & $\begin{array}{l}38 \\
(95 \%)\end{array}$ & 0 & $\begin{array}{l}2 \\
(5 \%)\end{array}$ & 0 & 0 & $\begin{array}{l}4 \\
(10 \%)\end{array}$ & 0 & $\begin{array}{l}36 \\
(90 \%)\end{array}$ \\
\hline 8 & $\begin{array}{l}4 \\
(10 \%)\end{array}$ & 0 & $\begin{array}{l}26 \\
(65 \%)\end{array}$ & 0 & 0 & 0 & 0 & $\begin{array}{l}40 \\
(100 \%)\end{array}$ \\
\hline 12 & 0 & 0 & $\begin{array}{l}9 \\
(22.5 \%)\end{array}$ & 0 & $\begin{array}{l}19 \\
(47.5 \%)\end{array}$ & 0 & $\begin{array}{l}12 \\
(30 \%)\end{array}$ & 0 \\
\hline 16 & 0 & 0 & $\begin{array}{l}3 \\
(7.5 \%)\end{array}$ & 0 & $\begin{array}{l}11 \\
(27.5 \%)\end{array}$ & 0 & $\begin{array}{l}26 \\
(65.5 \%)\end{array}$ & 0 \\
\hline 20 & 0 & 0 & 0 & 0 & $\begin{array}{l}3 \\
(7.5 \%)\end{array}$ & 0 & $\begin{array}{l}37 \\
(92.5 \%)\end{array}$ & 0 \\
\hline 24 & 0 & 0 & 0 & 0 & 0 & 0 & $\begin{array}{l}40 \\
(100 \%)\end{array}$ & 0 \\
\hline
\end{tabular}




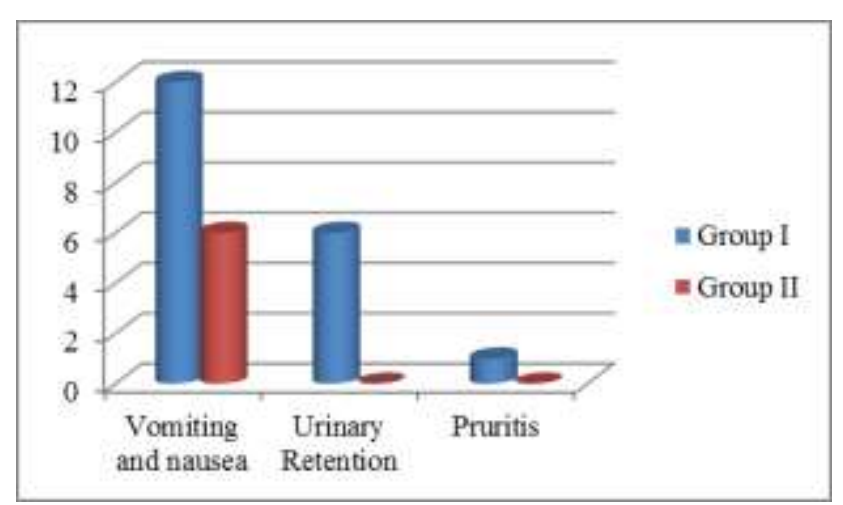

Figure 3: Side effects of analgesia.

\section{DISCUSSION}

Any method of postoperative analgesia must meet three basic criteria; it must be simple, safe, clinically appropriate and evidence based. ${ }^{9}$ Parentaral or intramuscular administrations of the opiod drugs are not as effective and the patients are left with unrelieved pain. ${ }^{10,11}$ The discovery of opioid receptors in the brain and spinal cord started a new era in the field of postoperative analgesia. ${ }^{12,13}$

The first clinical use of opiods was by Wang et al and since then, the use of opiods like buprenorphine was found to be more beneficial as a single intrathecal injection produces pain relief of sufficient duration. ${ }^{8}$

Buprenorphine was found to have a mixed agonistantagonist action. It has a high lipid solubility, high affinity for opoid receptors and has a prolonged duration of action, making it a good choice for intrathecal and peripheral nerve site administration.,

Weight, sex, height and age of patients showed no significance in our study. The onset of analgesia was $100 \%$ with buprenorphine within 5 mins of administration. $40 \%$ of these patients showed analgesic effect within 2 mins of administration itself. Only $50 \%$ of the patients showed an analgesic effect within 5 mins with only bipuvacaine. In a similar study by Sunil Dixit et at, $83 \%$ of the patients showed the onset of analgesia within 2 mins with buprenorphine and none at the same time with bipuvacaine alone, which was similar to our study. ${ }^{23}$

The duration of the analgesic effect in our study was on average over $15 \mathrm{hrs}$ with $20 \%$ of them extending upto 24 hours. $40 \%$ of the patients had 13-18 hours of duration of analgesia in Group I while with only bipuvacaine, the mean duration was less than 4 hours in all the 40 cases. Similar results were observed by Dixit et al in their study, corroborating our study. ${ }^{23}$

Addition of buprenorphine intrathecally or epidurally provides a good postoperative analgesia without prolonged motor block. ${ }^{14,15}$ A study by Shaloo Ipe et al observed that $150 \mathrm{mcg}$ buprenorphine was not as effective as $300 \mathrm{mcg}$ buprenorphine given epidurally where the duration of analgesia was highest, though the analgesic effect of buprenrphine given intrathecally was quite effective with $50 \%$ patients showing the effect for 6 hours. ${ }^{16}$ Some investigators have demonstrated that by using buprenorphine alone epidurally, in doses of 1 to 4 $\mathrm{mg}$, varying durations of pain relief ranging from 2.5 to 9 hours are observed. ${ }^{17,18}$ In yet another study by Sapkal Pravin et al, the duration of analgesia with buprenorphine was over 800 mins. Similar results were reported by Dixit and Shah et al. ${ }^{22,23}$

The efficacy of the analgesic was significantly better in Group I rather than Group II where pain was felt very early. Severe pain was felt in Group I only after 24 hours while $95 \%$ of the patients felt severe pain within 4 hours in Group II.

There were very few side effects in both the cases, only 6 patient in Group II had nausea, while in Group I, 12 patients had vomiting. Shaloo et al concorded with our study, where $20 \%$ of the patients given buprenorphine intrathecally had nausea and vomiting while other patients given the same drugs epidually did not $^{16}$. Previous studies show the incidence of pruritus after epidural administration of $50 \mathrm{mcg}$ fentanyl was $47 \%$ and with $300 \mathrm{mcg}$ Buprenorphine, 10\%. ${ }^{19}$ But in our study, only 1 patient in group I had pruritis while there were no cases in Group II. None of the patients in both the Groups had any episodes of respiratory distress. Sapkal et al observed $5 \%$ of patients with vomiting as side effects with buprenophine.

There were no incidence of backache, headache and drowsiness in our study, which was comparable to studies by Shaloo et al, Fuller JG et al and Escarment $\mathrm{J}$ et al. $^{16,20,21}$

\section{CONCLUSION}

Thus we conclude that intrathecal buprenorphine enhances sensory blockade of the local anesthetics without affecting the sympathetic activity. When compared to $0.5 \%$ bupivacaine alone, $0.5 \%$ bupivacaine along with low dosage of buprenorphine has superior anesthetic effect. The benefits of the opiods are far more than the side effects like vomiting and nausea. It is easily available, easy to perform and most predictable drug.

Funding: No funding sources

Conflict of interest: None declared

Ethical approval: The study was approved by the institutional ethics committee

\section{REFERENCES}

1. Kehlet H. Postoperative pain. In: Wilmore DW, Brennan M, Harken A, et al., eds. Care of the 
surgical patient. New York Scientific American Inc.; 1988:121-12.

2. Shukla D, Verma A, Agarwal A, Pandey HD, Tyagi C. Comparative study of intrathecal dexmedetomidine with intrathecal magnesium sulfate used as adjuvants to bupivacaine. J Anaesthesiol Clin Pharmacol. 2011;27(4):495-9.

3. Wu CL, Cohen SR, Richman JM, Rowlingson AJ, Courpas GE, Cheung K, et al. Efficacy of postoperative patient-controlled and continuous infusion epidural analgesia versus intravenous patient-controlled analgesia with opioids: A metaanalysis. Anaesthesiology. 2005;103:1079-88.

4. Carli F, Mayo N, Klubien K, Schricker T, Trudel J, Belliveau P. Epidural analgesia enhances functional exercise capacity and health related quality of life after colonic surgery: Results of a randomised trial.Anaesthesiology. 2002;97:540-9.

5. Celleno D, Capogna G. Spinal buprenorphine for postoperative analgesia after cesarean section. Acta Anaesthesiol Scand. 1989;33:236-8.

6. Miwa Y, Yonemura E, Fukushima K. Epidurally administered buprenorphine in the perioperative period.Can J Anaesth. 1996;43:907-13.

7. Lalla RK. Low dose intrathecal buprenorphine for postoperative analgesia. Indian J Anaesth. 1997;41:38-9.

8. Wang JK, Nauss LA, Thomas JK. Pain relief by intrathecally applied morphine in man. Anesthesiology. 1979;50:149-51.

9. Beilin B, Shavit Y, Trabekin E, Mordashev B, Mayburd E, Zeidel A, et al. The effects of postoperative pain management on immune response to surgery. Anesth Analg. 2003;97:822-7.

10. Moote C. Technique for postoperative pain management in the adult. Can J Anaesth. 1993;63:189-95.

11. Apfelbaum JL, Chen C, Mehta SS, Gan TJ. Postoperative pain experience: Results from a national survey suggest postoperative pain continues to be undermanaged. Anesth Analg. 2003;97:53440.

12. Bernards CM. Recent insights into the pharmacokinetics of spinal opiods and the relevance to opioid selection. Curr Opin Anarsthesiol. 2004; 17:441-7.

13. Bernards CM, Shen DD, Sterling ES, Adkins JE, Risler L, Phillips B, et al. Epidural, cerebrospinal fluid and plasma pharmacokinetics of epidural opioids: differences among opioids. Anesthesiology. 2003;99:455-65.

14. Govindarajan R, Bakalova T, Michael R, Abadir AR. Epidural buprenorphine in management of pain in multiple rib fractures. Acta Anaesthesiol Scand. 2002;46:660-5.

15. Goodman SR, Drachenberg AM, Johnson SA, Negron MA, Kim-Lo SH, Smiley RM. Decreased postpartum use of oral pain medication after a single dose of epidural morphine. Reg Anesth Pain Med.2005;30:134-9

16. Shaloo Ipe, Sara Korula, Sreelatha Varma, Grace Maria George, Sramma P Araham, Leena Rachel Koshy A comparative study of intrathecal and epidural buprenorphine using combined spinalepidural technique for caesarean section. Indian $\mathrm{J}$ Anaesth. 2010;54(3):205-9.

17. Abboud TK, Afrasiabi A, Zhu J, Mantilla M, Reyes A, D'Onofrio L, et al. Epidural morphine or butorphanol augments bupivacaine analgesia during labor. Reg Anesth. 1989;14:115-20.

18. Saxena AK, Arava SK. Current concepts in neuraxial administration of opioids and non-opioids: An overview and future perspectives. Indian $\mathrm{J}$ Anaesth. 2004;48:13-24.

19. Ackerman WE, Juneja MM, Kaczorowski DM, Colclough GW. A comparison of the incidence of pruritus following epidural opioid administration in the parturient. Can J Anaesth. 1989;36:388-91.

20. Escarment J, Clement HJ. Use of epidural and intrathecal opiates in obstetrics. Ann Fr Anesth Reanim.1989;8:636-49.

21. Fuller JG, Mc Morland GH, Douglas J, Plamer L. Epidural morphine for analgesia after caesarian sections. A report of 4880 patients. Can J Anaesth. 1990;37:636-40.

22. Shah FR, Halbe AR, Panchal JD, Goodchild CS. Improvement in postoperative pain relief by the addition of midazolam to an intrathecal injection of buprenorphine and bupivacaine. European Journal ofAnesthesiology. 2003;20:904-10.

23. Dixit S. Post-Operative Analgesia after Caesarean Section: An Experience with Intrathecal Buprenorphine. Indian Journal of Anaesthesia. 2007;51(6):515-8.

Cite this article as: Rao BD, Prakash KC.Comparative study of intrathecal bupivacaine $0.5 \%$ with bupivacaine $0.5 \%$ and buprenorphine low dose for postoperative analgesia in lower abdominal surgeries. Int Surg J 2016;3:253-7. 